\title{
Uma análise da produção de teses e dissertações sobre Objetos de Aprendizagem na área de Linguística e Letras
}

\section{An analysis of the production of theses and dissertations about Learning Objects in the area of Linguistics and Language learning}

\author{
Adilson Fernandes Gomes * \\ Alan Ricardo Costa ${ }^{* *}$ \\ Vanessa Ribas Fialho** \\ Luis Henrique dos Santos ${ }^{* * * *}$
}

Resumo: A proposta do presente trabalho é apresentar e discutir um mapeamento de teses e dissertações da área do conhecimento de Linguística e Letras que tenham como tema Objetos de Aprendizagem (OAs) para o ensino e a aprendizagem de línguas. Com vistas a identificar o estado da arte sobre OAs na área da Linguística Aplicada, foi utilizado na pesquisa, como ferramenta de busca, o Banco de Teses do Portal da Coordenação de Aperfeiçoamento de Pessoal de Nível Superior (CAPES). O corpus da pesquisa consiste em um total de 13 publicações referentes à área do conhecimento de Linguística e Letras, sendo 4 teses e 9 dissertações. Após a análise do corpus, conclui-se que a produção acadêmica relativa aos OAs no ensino de línguas ainda é limitada e que o tema carece de mais estudo por parte da comunidade acadêmica.

Palavras-chave: Objetos de Aprendizagem; Estado da Arte; Linguística e Letras.

Abstract: The proposal of the present paper is to bring forward and discuss a mapping of theses and dissertations from the Linguistics and Language learning knowledge area which has as theme Learning Objects (LOs) for teaching and learning of languages. Aiming to identify the state of the art about LOs in the area of Applied Linguistics, it was used in the research, as a research tool, the "Banco de Teses do Portal da Coordenação de Aperfeiçoamento de Pessoal de Nível Superior (CAPES)". The corpus of the research consists in a total of 13 different publications referring to the knowledge area of Linguistics and Language learning, being 4 theses and 9 dissertations. After a analysis of the corpus, it was concluded that the academic production relative to the LOs on language learning is still limited and the theme needs more studying by the academic community.

Keywords: Learning Objects; State of the Art; Linguistics and Language learning.

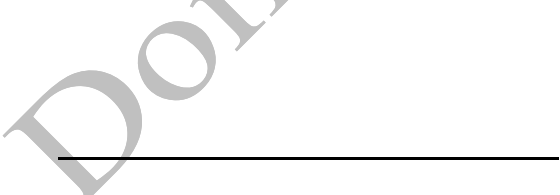

\footnotetext{
* Especialista em Metodologia do Ensino de Língua Portuguesa e Estrangeira (UNINTER), Graduando em Licenciatura em Letras, Habilitação em Inglês e Literatura da Língua Inglesa (UFSM), Bolsista do Programa Institucional de Voluntários em Iniciação Científica (PIVIC), adilson.fernandesgomes@gmail.com;

** Acadêmico do curso de Licenciatura em Letras, Habilitação em Espanhol e Literaturas de Língua Espanhola, da Universidade Federal de Santa Maria (UFSM). Bolsista de Iniciação Científica pelo Conselho Nacional de Desenvolvimento Científico e Tecnológico (CNPq), alan.dan.ricardo@gmail.com;

*** Professora adjunta do Departamento de Letras Estrangeiras Modernas (DLEM) da Universidade Federal de Santa Maria (UFSM). Doutora em Linguística Aplicada pela Universidade Católica de Pelotas, vanessafialho@gmail.com;

**** Acadêmico do curso de Licenciatura em Letras, Habilitação em Espanhol e Literaturas de Língua Espanhola, da Universidade Federal de Santa Maria (UFSM). Bolsista de Iniciação Científica pelo Conselho Nacional de Desenvolvimento Científico e Tecnológico (CNPq), luislhshenrique@gmail.com.
} 


\section{Introdução}

Dentro da área da Linguística Aplicada, tem-se discutido em eventos e publicações acadêmicas o papel dos Objetos de Aprendizagem (OAs) no ensino de línguas. No entanto, ainda não há um consenso quanto à definição teórica de OAs, mas podem ser considerados como qualquer coisa digital com objetivo educacional (McGREAL, 2004; LEFFA, 2006).

A importância e a atenção dadas aos OAs são justificáveis principalmente porque, entre outros motivos, tais objetos facilitam o processo de construção do conhecimento, pois oferecem recursos que levam o aluno a interagir com o conteúdo, a investigar problemas, a testar hipóteses e aprimorar ideias (LIMA; HAGUENAUER, 2011). É importante lembrar, ainda, que os OAs estão a serviço do processo de ensino e aprendizagem, no sentido de que levam os alunos a se envolverem de forma ativa nesse processo, contribuindo para uma aprendizagem mais significativa.

O presente trabalho desenvolve-se no âmbito do projeto de pesquisa "A produção de OAs para o ensino de E/LE ${ }^{1}$, , o qual tem como objetivo cumprir com a primeira etapa de atividades do projeto, ou seja, realizar um levantamento de estudos teóricos e práticos recentes que embasam os OAs para o ensino de línguas.

Considerando a necessidade de conhecer a bibliografia que envolve os OAs, a partir de um panorama geral de publicações acadêmicas de Instituições de Ensino Superior (IES) do Brasil, a fim de termos ciência sobre as produções acadêmicas já publicadas, do que já tem sido feito e, também, quais os resultados que já foram obtidos em pesquisas sobre OAs, explicitamos o objetivo do presente trabalho, que se resume em apresentar um mapeamento em nível nacional de teses e dissertações da área do conhecimento de Linguística e Letras, que tenham como tema os OAs para o ensino e a aprendizagem de línguas.

Esta pesquisa se justifica tendo em vista que esse mapeamento é de profundo interesse para o grupo de pesquisa, uma vez que mostrará o estado da arte sobre o tema a ser investigado. Dessa forma, servirá para que possamos direcionar as pesquisas do projeto, bem como auxiliará na delimitação de uma linha teórica de ação.

Para melhor entendimento da proposta, este artigo é composto pelas seguintes seções: após esta introdução, na segunda seção, realizamos uma reflexão sobre as pesquisas e estudos do estado da arte dos OAs. Na terceira seção, apresentamos as concepções e exemplos de

\footnotetext{
${ }^{1}$ Projeto de pesquisa registrado pelo número 026218 no Gabinete de Projetos do Centro de Artes e Letras (GAP/CAL), da Universidade Federal de Santa Maria (UFSM).
} 
OAs, bem como os repositórios de OAs específicos para o ensino de línguas. A quarta seção contém a metodologia da pesquisa, já na quinta seção, são apresentados os resultados encontrados e as respectivas discussões. A sexta e última seção resume as considerações finais mais relevantes desta pesquisa.

\section{Foco no estado da arte}

Com base em Reis (2008), ressaltamos que o estabelecimento de panoramas gerais e agendas de pesquisa, de diferentes temas, tem sido foco de investigação de diversos pesquisadores da área da Linguística Aplicada na última década.

A partir dessa visão, em 2008, a autora publicou um estudo cujo escopo era a identificação das teorias que têm orientado as diferentes fases de pesquisas em Computer Assisted Language Learning (CALL), aprendizagem de línguas mediada por computador no Brasil. Para isso, Reis (2008) focou-se na investigação dos objetivos das pesquisas e as tendências teóricas publicadas em artigos, dissertações e teses da área.

Um ano depois, Paiva, Silva e Gomes (2009) publicaram uma investigação científica similar, referente a um levantamento panorâmico das temáticas e das perspectivas teóricas e metodológicas mais recorrentes nas pesquisas da Linguística Aplicada, em âmbito nacional e internacional. Para esse levantamento, sete periódicos internacionais e cinco nacionais foram analisados, tendo como prioridade de investigação os seguintes aspectos: temas, teorias e metodologias.

Outra publicação relevante foi realizada por Paiva (2005), a qual apresenta um levantamento, no Brasil e no exterior, com o foco de investigação nos métodos de pesquisa e na interação e aprendizagem de línguas mediadas pelo computador. A partir desse levantamento, são ídentificados os instrumentos que têm sido mais utilizados para estudar os temas recorrentes, tais como o impacto das novas tecnologias na aprendizagem de línguas no ambiente virtual (Ibdem).

$\mathrm{O}$ que as supracitadas pesquisas têm em comum, além do fato de estarem inseridas na área da Linguística Aplicada, é justamente a aparente necessidade de responder o que está acontecendo aqui? - pergunta bastante característica de investigações de cunho etnográfico, como lembra Paiva (2005). Em outras palavras, as pesquisas compartilham a noção de que o estabelecimento de agendas de investigações científicas, mapeamentos e panoramas gerais de estudos acadêmicos são alternativas favoráveis ao pesquisador, que tem a seu alcance os 
resultados obtidos em anos de pesquisas do passado, e, dessa maneira, subsídios para explorar pesquisas no futuro.

De certo modo, as publicações citadas anteriormente legitimam a importância de um mapeamento de produções acadêmicas e, por conseguinte, justificam o presente artigo, pois propomo-nos, seguindo a mesma perspectiva dos autores antes referenciados, expor a situação de publicações acadêmicas (teses e dissertações), em nível nacional, na área do conhecimento de Linguística e Letras, que tratem de OAs para o ensino e aprendizagem de línguas.

Esse mapeamento se mostra uma medida importante e possivelmente muito promissora para o projeto sobre OAs, uma vez que a consignação de um panorama de publicações acadêmicas pode apontar aos pesquisadores do projeto o que já tem sido feito e quais resultados que já foram obtidos sobre OAs, tanto no processo de ensino e aprendizagem em geral, quanto no processo de ensino e aprendizagem de línguas em particular, contribuindo, assim, com a delimitação de futuras pesquisas, além de servir como base para as atividades que serão desenvolvidas no projeto.

Direcionando a discussão mais especificamente para a questão dos OAs para o ensino de línguas, ressalvamos que o estudo do estado da arte pode contribuir com a identificação da popularidade (ou impopularidade) dos OAs na área da Linguística Aplicada. Leffa, em 2006, apontou a necessidade de aumentar a oferta de OAs direcionados para o ensino de línguas, uma vez que esses objetos não haviam causado na educação, em geral, e no ensino de línguas, em particular, o impacto esperado por seus proponentes. Portanto, pretendemos que o estudo do estado da arte possibilite uma visão da popularização de OAs no ambiente acadêmico de nível superior, a partir do mapeamento e análise das publicações, teses e dissertações, nacionais, bem como pelo levantamento das Instituições de Ensino Superior (IES) e dos Programas de Pós-Graduação (PPGs) que pesquisam e publicam sobre os referidos OAs.

$\mathrm{Na}$ sequência, serão expostas algumas definições destinadas aos OAs, bem como apresentaremos exemplos de OAs para o ensino e aprendizagem de línguas disponíveis na Internet.

\section{Definições e objetos de aprendizagem}

No tocante a uma definição de OA, é importante acrescentar que a comunidade acadêmica ainda não chegou a um consenso final sobre uma definição específica. $\mathrm{O}$ conceito de OA pode variar segundo a área de discussão ou os autores que procuram defini-los. 
Nesse viés, Leffa (2006) leva em consideração o estudo de McGreal (2004) e expõe resumidamente quatro possíveis correntes de perspectivas teóricas. Essas perspectivas fazem um apanhado geral das muitas definições que os OAs podem receber, para isso, as agrupa em uma escala hierárquica que vai desde os conceitos mais amplos até os mais específicos:

(1) Qualquer coisa: pode ser um livro, um computador, ou mesmo uma vassoura, o que o torna um OA, é o uso que é feito dele para o ensino.

(2) Qualquer coisa digital: é mais restrito do que "qualquer coisa", mas para ser uma definição útil precisa levar em conta os objetivos para os quais foram elaborados os arquivos digitais.

(3) Qualquer coisa com objetivo educacional: um livro, uma calculadora, um microscópio, um programa de computador, uma página da Web, pode ser um OA, sem haver uma diferença entre digital ou não digital

(4) Qualquer coisa digital com objetivo educacional: Esse sendo um conceito dominante de OA, pois pode ser qualquer arquivo digital (texto, imagem, ou vídeo), desde que usado para facilitar e promover a aprendizagem (LEFFA, 2006, p. 5).

Este último conceito concorda com a concepção de OA de Garcia (2011, p. 21), que define essa ferramenta como "recursos pedagógicos digitais para o ensino mediado por computador, cujo planejamento e apresentação do conteúdo devem ser embasados em uma teoria de aprendizagem".

Para melhor visualizarmos, apresentamos o OA Agrega ${ }^{2}$ é destinado ao ensino de língua espanhola e é encontrado gratuitamente na internet. Esse objeto é destinado aos alunos do segundo ciclo da educação primária, na disciplina de matemática. Tem como objetivo geral, destacado no guia do professor, utilizar corretamente os números naturais até seis algarismos. Para isso, os alunos devem ler, escrever e ordenar números; reconhecer o valor posicional das cifras; estabelecer corretamente a classificação de números pares e ímpares; ordenar corretamente a classificação dos números dados; decompor os números em forma aditiva ou aditivo-múltipla atendendo o valor posicional de suas cifras.

Ó Agrega utiliza como título Los números naturales menores que el millón e foi produzido pela Entidade Pública Empresarial Red.es, no Programa Internet na Escola. As atividades encontram-se em língua espanhola com uma proposta pedagógica multidisciplinar, envolvendo a disciplina de matemática e conhecimentos gerais, entre outras.

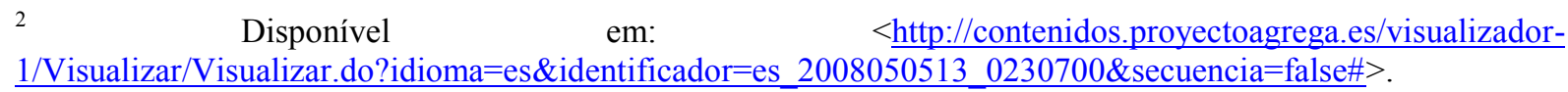




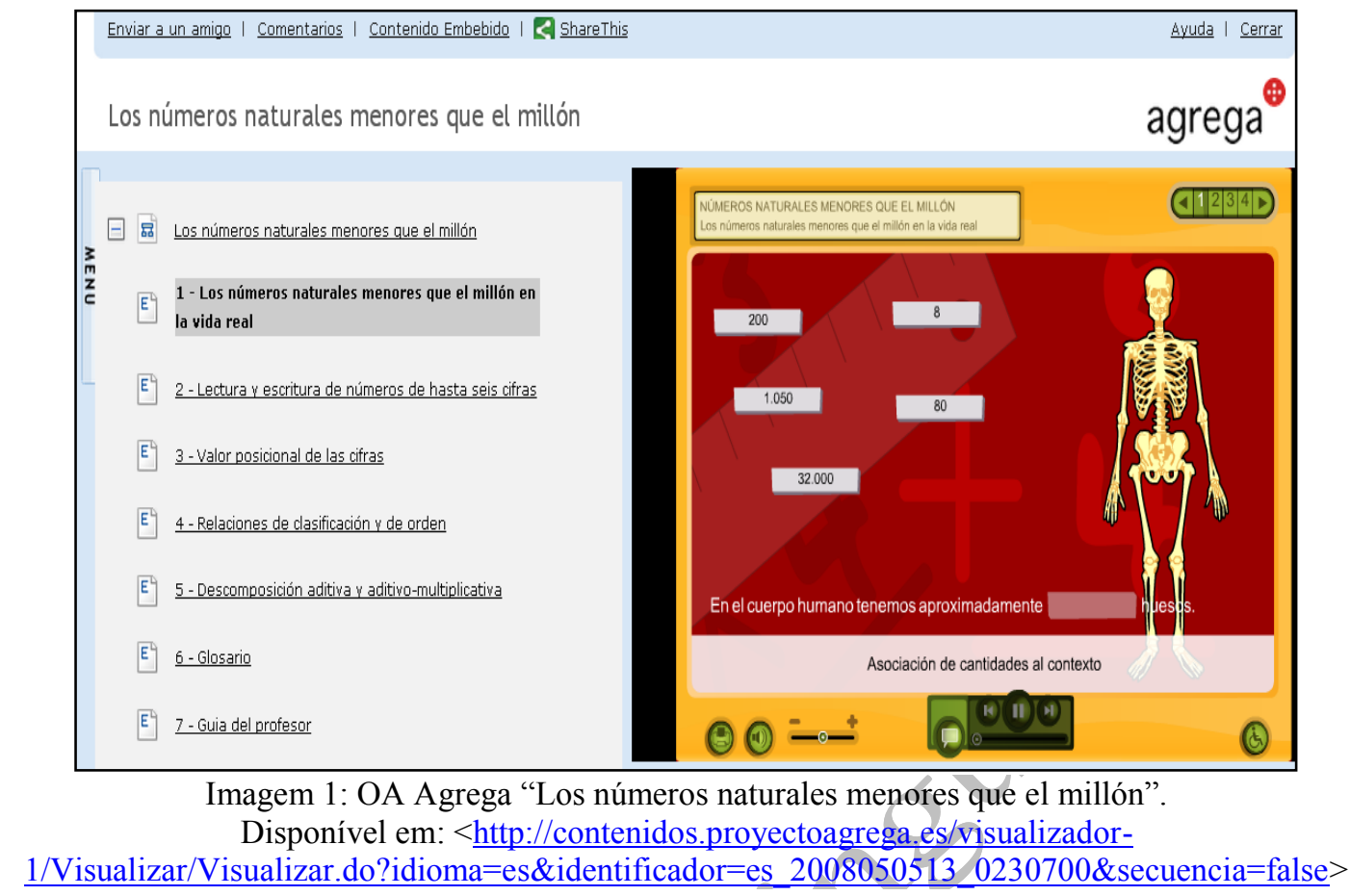

Esse OA é composto por oito atividades definídas no menu: Los números naturales menores que un millón en la vida real; Lecturas y escritura de números hasta seis cifras; Valor posicional de las cifras; Relaciones de clasificación y de orden; Descomposición aditiva y aditiva-multiplicativa; Glosario; Guía del profesor; Ayuda.

A definição de OA destinado ao ensino de línguas, na perspectiva de Garcia (2011), recursos pedagógicos digitais para o ensino mediado por computador, pode ser considerada bastante pertinente e condizente com os estudos atuais da área da Linguística Aplicada, uma vez que leva em consideração o ambiente virtual onde OAs estão inseridos. Hoje em dia, é comum (ou espera-se) que OAs fiquem armazenados em repositórios, com vistas a facilitar seu (re)uso por parte dos professores e alunos. Assim, considerando que um OA é um objeto digital para fins de ensino mediado por computador, é natural pensar em ambientes que sirvam como repositórios virtuais de OAs.

Nesse sentido, Lima e Haguenauer (2011) afirmam que os repositórios de OAs são locais que fornecem acesso aos mais variados tipos de OAs para o contexto educacional. Dessa maneira, funcionam como uma biblioteca, onde são catalogados para que a busca se torne mais rápida e eficiente. 
Para visualizarmos os repositórios virtuais de OA, apresentamos o projeto Rede Internacional Virtual de Educação (RIVED) ${ }^{3}$, o qual é um projeto de cooperação entre países da América Latina (Brasil, Venezuela e Peru).

O RIVED, com o propósito de contribuir com o fomento da produção de conteúdos pedagógicos digitais, na forma de objetos de aprendizagem, trabalha principalmente com atividades multimídia interativas na forma de animações e simulações. É oportuno ressaltar que os OAs do RIVED vêm acompanhados de um guia do professor com sugestões de uso, na intenção de contribuir com o trabalho docente.

No entanto, um aspecto negativo do RIVED está relacionado em não ofertar OAs para o ensino de E/LE, apesar de ser um projeto custeado pelo Ministério da Educação e Comunicação (MEC), órgão que incentiva o ensino de espanhol como língua estrangeira nas escolas, através da lei 11.161, de 11 de agosto de 2005, e, ainda, pela inclusão da língua espanhola no Plano Nacional do Livro Didático - PNLD.

Outro exemplo de repositório de OAs é o ELO - Ensino de Línguas Online. Esse repositório tem como base um sistema de autoria para a produção de objetos interativos de aprendizagem voltados para o ensino de línguas, tais como: inglês, português, espanhol e latim.

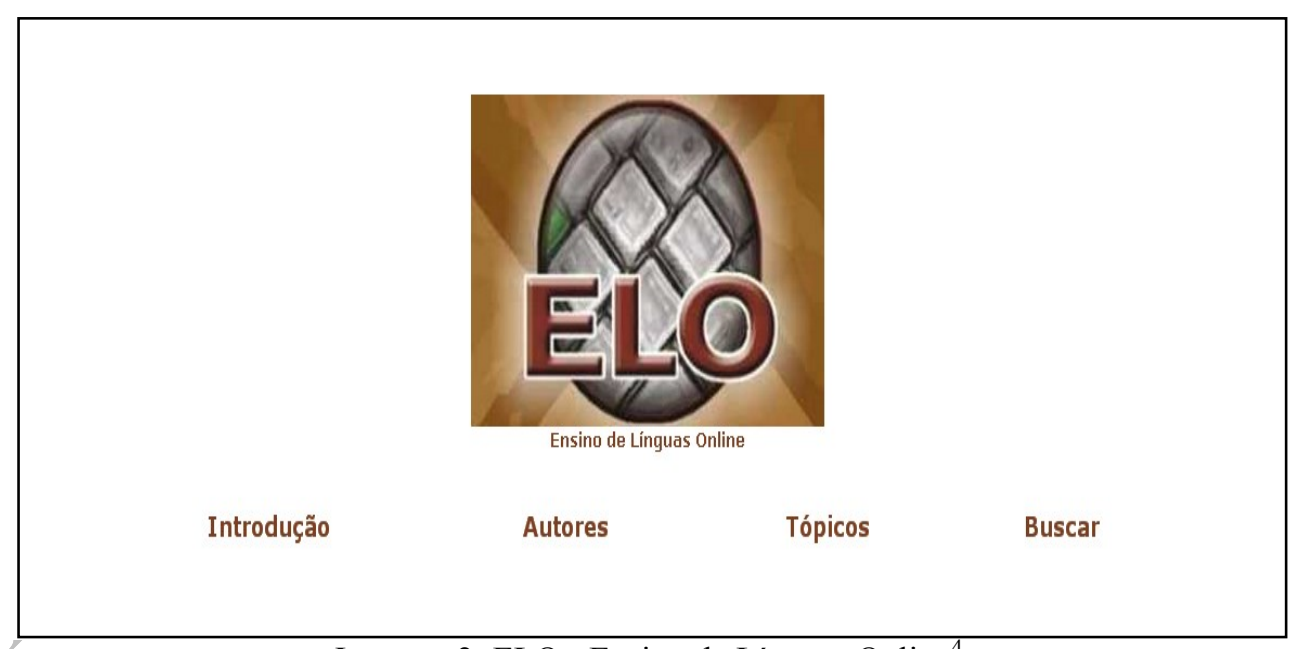

Imagem 2: ELO - Ensino de Línguas Online ${ }^{4}$.

Disponível em: $<\underline{\text { http://www.leffa.pro.br/elo/repositorio/index.html }>}$

Sendo uma ferramenta de autoria desenvolvida dentro do projeto Ensino de Línguas Online, inicialmente, armazenava OAs para o ensino de línguas produzidos pelos professores

\footnotetext{
${ }^{3}$ Disponível em: $<$ http://rived.mec.gov.br/>.

${ }^{4}$ Para saber mais sobre o ELO, repositório construído pelo professor PhD em Linguística Aplicada Vilson José Leffa, da Universidade Católica de Pelotas, visite: < http://www.leffa.pro.br/elo/index.html $>$.
} 
envolvidos no projeto. Posteriormente, foi aberto para a colaboração dos professores não participantes do projeto, os quais poderiam disponibilizar os seus OAs.

Dentre os muitos aspectos que tornam o ELO recomendado por professores de espanhol, destacamos: 1) apresenta diversos tipos de OAs para o ensino de E/LE; 2) não exige instalação e não dissemina arquivos pelo HD e pode ser copiado diretamente para uma pasta no computador; 3 ) permite a construção de diversos tipos de OAs, como atividades de jogo de memória, questões de múltipla escolha, perguntas abertas, entre outras.

É necessário ressalvar que os OAs destacam-se como recursos educacionais capazes de aferir um caráter dinâmico, interativo, flexível e motivador ao processo educativo (SILVA; FAGUNDES; BASSO, 2008). Dessa maneira, era de se esperar que os OAs causassem na educação um impacto significativo concernente à realidade da academia.

Dessa forma, alguns autores em Linguística Aplicada defendem que esse impacto vem acontecendo nesses últimos anos. Garcia (2011), por exemplo, argumenta que os OAs têm despertado cada vez mais interesse de estudiosos da área de tecnologia e de educação. Entretanto, o interesse despertado ainda não tenha sido suficientemente expressivo para manter o assunto em discussão. Essa perspectiva ratifica os resultados apontados por Leffa, em 2006, ao apontar que os OAs talvez ainda não haviam causado na educação, em geral, e no ensino de línguas, em particular, o impacto esperado por seus proponentes.

Na próxima seção, apresentaremos a metodologia empregada nessa pesquisa.

\section{Metodologia}

A metodologia empregada consiste em levantamento quantitativo e qualitativo de publicações acadêmicas que tematizam principalmente questões como elaboração, utilização e avaliação de OAs de línguas. O procedimento empregado consiste em um mapeamento de teses e dissertações que tenham como tema OAs e que podem ser acessados a partir do Portal da Coordenação de Aperfeiçoamento de Pessoal de Nível Superior ${ }^{5}$ (CAPES).

Como ferramenta inicial de busca online, optamos por utilizar o Banco de Teses ${ }^{6}$, como mostra a Imagem 3, que faz parte do Portal da CAPES. Consideramos que esse local de armazenamento de produções seja importante por desempenhar um "papel relevante no desenvolvimento, na expansão e na consolidação da pesquisa em todo o Brasil, sendo órgão

\footnotetext{
${ }^{5}$ Disponível em: <http://www.capes.gov.br/>.

${ }^{6}$ Disponível em: <http://capesdw.capes.gov.br/capesdw/>.
} 
máximo no que diz respeito à avaliação da pós-graduação stricto sensu" (LIMA; LIMANETO, 2010, p. 50). Com isso, acreditamos que o universo da CAPES abarque as investigações mais sólidas no contexto acadêmico brasileiro referente aos OAs, pois "essa entidade abrange todos os vinte seis estados da federação" (LIMA; LIMA-NETO, 2010, p. 50), bem como o Distrito Federal.

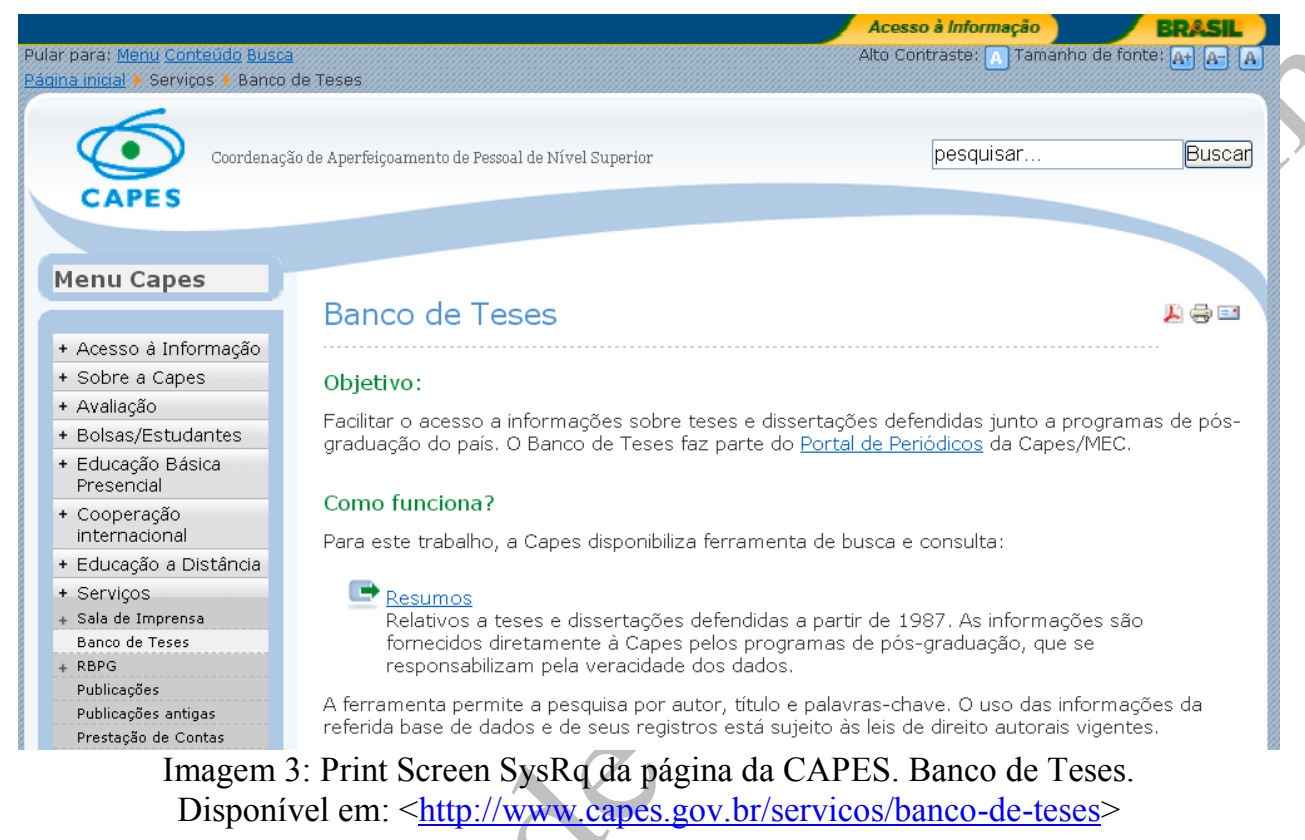

Essa ferramenta de busca engloba um acervo de dissertações e teses defendidas a partir de 1987. Como o próprio site aponta, as informações são fornecidas diretamente a CAPES pelos programas de pós-graduação, que se responsabilizam pela veracidade dos dados. Além disso, outro motivo que nos levou a optar pelo Banco de Teses foi a praticidade, pois o mesmo permite a pesquisa por autor, título e palavras-chave.

Como palavras-chave empregadas para nortear a pesquisa (Imagem 4) utilizamos o termo "Objetos de Aprendizagem" no campo "Assunto". Antes de efetuarmos a pesquisa, selecionamos a opção "expressão exata", com vistas a evitar resultados referentes às opções "todas as palavras" e "qualquer uma das palavras" que são as demais opções da ferramenta do campo de busca do site, o que poderia nos devolver resultados que falassem de objetos e/ou de aprendizagem. O nível escolhido para orientar a busca por teses, evidentemente, foi "Doutorado", enquanto que para a busca por dissertações foi "Mestrado"; no campo "Nível/ano base” o período selecionado foram os anos de 2004 a 2011.

É oportuno esclarecer que o ano de 2004 foi considerado como o ano inicial de busca porque, antes disso, no Brasil, pesquisas sobre OAs no ensino de línguas ainda não eram 
populares, e, como um todo, esse assunto em âmbito acadêmico não era de fato significativo. Por outro lado, é válido explicar que o ano de 2012 não foi incluído na busca visto que os dados de produções acadêmicas, referentes a este ano, ainda não estão disponíveis no Portal, pelo menos até a data da coleta dos dados para esta investigação (período de maio a julho de 2012).

Os campos como "Autor" e "Instituição" foram propositalmente ignorados com vistas à obtenção de um maior número de resultados na busca online, como pode ser visto na Imagem 4, a seguir.

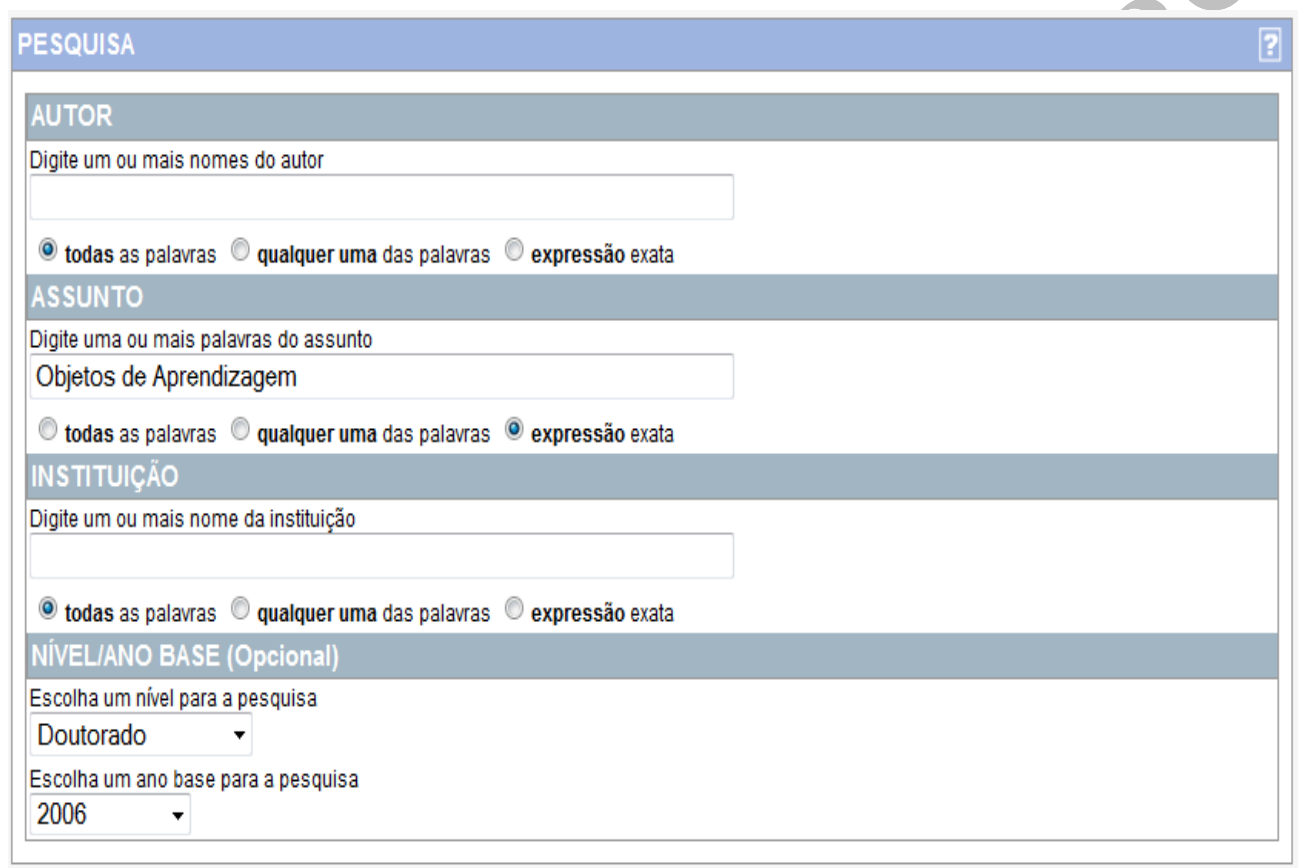

Imagem 4: Exemplo de busca de teses do ano de 2006.

Para a coleta de dados e informações no corpus da pesquisa, valemo-nos da metodologia seguida por Paiva, Silva e Gomes (2009): montagem de planilhas com os títulos e respectivos autores de todos os textos, juntamente com o ano da publicação, as grandes áreas e as áreas específicas. Resumidamente, efetuamos uma leitura do resumo de cada texto a partir da estratégia de scanning ${ }^{7}$, para localizar as informações referentes ao uso de OAs. A justificativa para adoção da metodologia de leitura dos resumos foi por considerar que, após a leitura, tem-se uma ideia geral do que será encontrado na íntegra do texto, pois o resumo "tem

${ }^{7}$ Estratégia de leitura que consiste na obtenção dinâmica de uma ou mais informações do texto, sem a necessidade de leitura linear e/ou de todas as palavras. É uma leitura de visualização rápida do texto, onde o objetivo é encontrar algo específico, sendo que o leitor sabe o que está procurando. 
o objetivo de sumarizar, indicar e predizer, em um parágrafo curto, o conteúdo e a estrutura do texto integral que segue" (MOTTA-ROTH; HENDGES, 2010, p. 153).

As atividades de buscas das teses e dissertações disponíveis online, bem como a leitura e análise dos resumos das publicações foram efetuadas nos meses de maio, junho e julho do ano de 2012. A seguir, daremos conhecimento sobre os resultados obtidos por meio do levantamento das teses e dissertações que abordam o tema OAs de línguas.

\section{Resultados e discussões}

Ao efetuarmos o levantamento de textos acadêmicos no Portal CAPES, localizamos um total de 229 trabalhos nas mais diversas áreas do conhecimento, entre teses e dissertações (Quadro 1). Chegamos a esse número de trabalhos, como já explicitamos, através da expressão exata “Objetos de aprendizagem” no Banco de Teses do Portal da CAPES.

Com o propósito de visualizar a produção acadêmica de teses e dissertações e uma possível popularização da temática, estabelecemos no quadro a seguir um panorama quantitativo de publicações acadêmicas nos últimos oito anos.

Quadro 1 - Teses e Dissertações

\begin{tabular}{llll}
\hline Ano & Teses & Dissertações & Total \\
\hline 2004 & 2 & 5 & 7 \\
2005 & 2 & 13 & 15 \\
2006 & 4 & 23 & 27 \\
2007 & 5 & 20 & 25 \\
2008 & 8 & 20 & 28 \\
2009 & 9 & 38 & 47 \\
2010 & 11 & 35 & 46 \\
2011 & 6 & 28 & 34 \\
Total & 47 & 182 & 229 \\
\hline
\end{tabular}

Fonte: Dados do Portal CAPES, 2012.

Analisando o Quadro 1 observamos que o período mais produtivo de trabalhos relativos a temática dos OAs consiste entre os anos de 2009 a 2011, com um total de 127 (teses e dissertações) equivalendo a 55,46\% das publicações do período, entre todas as áreas. 
No nível de Doutorado é possível destacarmos o ano de 2010 como sendo o de maior produção, com o número de 11 teses, referindo-se a 23,40\% do período. Já no nível de Mestrado, o ano 2009 foi o mais produtivo com 38 dissertações, equivalendo a 20,88\% das produções do período.

Diante dos resultados obtidos, verificamos que houve um aumento significativo nas produções dos OAs no período investigado. Esse aumento é significativo em teses e dissertações, mas é oportuno salientarmos que engloba todas as áreas do conhecimento. A seguir, buscaremos evidenciar a produção dentro de cada área do conhecimento.

\section{1. Áreas do conhecimento}

No contexto de investigação, visualizar em que área do conhecimento estão sendo produzidos os OAs torna-se relevante e essencial para a compreensão e entendimento do universo teórico e prático a ser pesquisado. Assim, o Quadro 2 apresenta um panorama geral sobre as áreas do conhecimento das teses e dissertações encontradas do período de 2004 a 2011.

Quadro 2 - Teses e Dissertações por Áreas do Conhecimento

\begin{tabular}{lccc}
\hline Áreas do conhecimento & Teses & Dissertações & Quantidade \\
\hline Administração & - & 2 & 2 \\
Anatomia Patológica e Patologia & 3 & - & 3 \\
Clínica & 2 & 4 & 6 \\
Banco de dados & 1 & - & 1 \\
Bioquímica & 2 & 24 & 26 \\
Ciências da Computação & - & 2 & 2 \\
Ciências Exatas e da Terra & - & 1 & 1 \\
Ciências da Saúde & - & 1 & 1 \\
Ciências Sociais Aplicada & 1 & - & 1 \\
Comunicação & - & 3 & 3 \\
Desenho Industrial & 8 & 40 & 48 \\
Educação & 1 & - & 1 \\
Educação Artística & - & 1 & 1 \\
Educação Especial & - & 1 & 1 \\
Endodontia & - & 1 & 1 \\
Enfermagem & - & 1 & 1 \\
Engenharia & 2 & 2 & 4 \\
Engenharia Elétrica & 1 & - & 1 \\
Engenharia Mecânica & 1 & 1 & 2 \\
Engenharia de Produção & - & 1 & 1 \\
Engenharia de Software & - & 1 & 1 \\
Ensino & - & 1 & 1 \\
Ensino e Aprendizagem na Sala & & & \\
& & & 1 \\
\hline
\end{tabular}




\begin{tabular}{|c|c|c|c|}
\hline Ensino de Ciências e Matemática & 2 & 9 & 11 \\
\hline Estatística & - & 1 & 1 \\
\hline Fonoaudiologia & - & 1 & 1 \\
\hline Geografia & - & 1 & 1 \\
\hline Letras & - & 2 & 2 \\
\hline Linguística Aplicada & 3 & 2 & 5 \\
\hline Linguística, Letras e Artes & - & 3 & 3 \\
\hline Língua Estrangeira Moderna & - & 1 & 1 \\
\hline Matemática & 1 & - & 1 \\
\hline Psicologia & - & 1 & 1 \\
\hline Psicologia Cognitiva & - & 1 & 1 \\
\hline Química & - & 1 & (1) \\
\hline Sistema de Computação & - & 2 & 2 \\
\hline Sistema de Informação & - & 1 & 1 \\
\hline Tecnologia Educacional & 1 & 2 & 3 \\
\hline Teoria e Análise Linguística & - & 1 & 1 \\
\hline $\begin{array}{l}\text { Mais de uma área do } \\
\text { conhecimento }\end{array}$ & 4 & 38 & 42 \\
\hline Não apresentaram a informação & 14 & 28 & 42 \\
\hline Total & 47 & 182 & 229 \\
\hline
\end{tabular}

Fonte: Dados do período de 2004 a 2011, Banco de teses da CAPES 2012.

Os dados do Quadro 2 foram retirados dos resumos das teses e dissertações, do Banco de Teses, do Portal da CAPES e, como podemos observar, pertencem a diferentes áreas do saber. Ao focarmos as subáreas que compõe a área da Linguística e Letras, observamos que a variedade de publicação é reduzida, como é evidenciado na subárea de Língua Estrangeira Moderna, a qual tem apenas uma produção.

$\mathrm{Na}$ análise dos resumos, observamos que muitos autores, ao publicarem os seus textos no Portal da CAPES, através de seus programas de pós-graduação, cadastram na área do conhecimento expressões referentes às grandes áreas do saber. Esse exemplo é caracterizado nas produções cadastradas como Linguística, Letras e Artes, a qual se refere à grande área do conhecimento e não é considerada uma área do conhecimento, como "Linguística/Letras" ou “Artes/Música”.

É válido registrar que os autores de 42 produções (14 teses e 28 dissertações) ao preencherem os campos solicitados para cadastrar o resumo no Banco de Teses no Portal da CAPES, não acrescentaram os dados referentes à área do conhecimento. Com isso, não foi possível a identificação desse campo e, consequentemente, esses OAs não foram alvo de análise. Outra situação encontrada foi a existência de 42 publicações, sendo 4 teses e 38 dissertações, os autores apresentaram mais de uma área do conhecimento. No entanto, 
entendemos que estar incluído em "mais de uma área do conhecimento" significa estar dentro de uma grande área. Com isso, essas publicações estarão sujeito a análise.

Ao focarmos nas 42 publicações que os autores não disponibilizaram a área do conhecimento $(18,34 \%)$, constatamos que não há uma preocupação por parte desses autores em fornecer as informações corretas ao cadastrarem seus trabalhos no portal CAPES.

Neste artigo, o foco de investigação no processo de análise dos resumos está centrado na área de conhecimento de Linguística e Letras, que segundo a relação fornecida pela $\mathrm{CAPES}^{8}$, envolve as seguintes especificações encontradas no Quadro 2: Teoria e Análise Linguística, Linguística Aplicada, Letras, Línguas Estrangeiras Modernas.

Nesse sentido, todas as teses e dissertações que utilizaram uma dessas expressões como áreas do conhecimento foram selecionadas para análise do resumo. Entre as teses com mais de uma área do conhecimento encontramos uma que apresentou especialização da área de Linguística e Letras (Linguística Aplicada e Línguas Estrangeiras Modernas) e foi incluída junto aos textos para análise. Com isso, pode-se contar com um corpus de 13 trabalhos acadêmicos, sendo 4 teses e 9 dissertações da área de Linguística e Letras.

Para darmos sequência na análise das teses e dissertações com o foco na produção dos OAs, apresentaremos a análise das publicações dentro da área do conhecimento de Linguística e Letras.

\subsection{Publicações na área do conhecimento de Linguística e Letras}

Na perspectiva de identificarmos quais são os Programas de Pós Graduação (PPG) que pesquisam e publicam no Brasil, bem como os títulos das teses e dissertações, autoria e ano de produção, destacamos o Quadro 3 por apresentar um apanhado específico sobre o contexto dos OAs para ensino de línguas.

Quadro 3 - Produção na Área do Conhecimento: Linguística, Letras e Artes

\begin{tabular}{llll}
\hline \multicolumn{1}{c}{ Título } & Autor & Ano & $\begin{array}{l}\text { Programa de } \\
\text { Pós-Graduação }\end{array}$ \\
\hline $\begin{array}{l}\text { A sala de aula digital sob a perspectiva dos } \\
\text { sistemas complexos: uma abordagem } \\
\text { qualitativa. }\end{array}$ & $\begin{array}{l}\text { Vicente } \\
\text { Aguimar } \\
\text { Parreiras }\end{array}$ & 2005 & $\begin{array}{l}\text { UFMG, Estudos } \\
\text { Linguísticos } \\
\text { (Doutorado) }\end{array}$
\end{tabular}

\footnotetext{
${ }^{8}$ Disponível em: $<\underline{\text { http: } / / w w w . c a p e s . g o v . b r / a v a l i a c a o / t a b e l a-d e-a r e a s-d e-c o n h e c i m e n t o />>. ~}$
} 
As crenças de aprendizagem de línguas de principiantes brasileiros adultos sobre a escrita em um curso de espanhol como língua estrangeira.

Autoria e condições de produção textual no ambiente pedagógico colaborativo - APC do Portal Dia a dia - Educação do Paraná.
Idelso

Espinola Taset

2006 UnB,

Aplicada

(Mestrado)

Wanderley 2006 UEM, Letras

Braga

(Mestrado)

O papel dos objetos de aprendizagem no ensino de línguas: uma análise em cursos on-line de espanhol como língua estrangeira.

Uma compreensão etnometodológica da aprendizagem de língua estrangeira na falaem-interação de sala de aula.

Arice Cardoso

2007

Tavares

UCPel, Letras

Maria de la O

2008 UFRGS, Letras

López

Abeledo (Doutorado)

A canção popular autêntica aplicada ao processo de ensino-aprendizagem da língua alemã como língua estrangeira São Paulo.

Carin Beatriz

008 USP, Letras

A produção escrita dos professores da rede pública estadual, para ser postada no Portal Dia-a-dia Educação: mapa ou decalque?

Carreira

Zachariadis

Helena

Miyoko Miura

da Costa

2008 UNIOESTE,

Luciana do

A hipótese da neutralidade teórica e os objetos de aprendizagem para o ensino da língua inglesa: um estudo de caso.

Amaral (Mestrado)

Aprendizagem da leitura: contribuições e Greici Quéli limitações dos métodos de ensino fônico e Machado global na alfabetização de crianças.

A auto-avaliação em um contexto de ensinoaprendizagem de línguas em tandem via chat.

Suzi Marques

Spatti Cavalari

O frame princesa de contos de fada: um estudo do descritivo visando à elaboração de um objeto de aprendizagem para a prática de leitura.

Objetos de aprendizagem como artefatos mediadores da construção do conhecimento: um estudo com base na epistemologia histórico-cultural.

\begin{tabular}{|c|c|c|}
\hline $\begin{array}{l}\text { O trabalho interacional para a } \\
\text { reconfiguração de atividades pedagógicas } \\
\text { instrucionais na sala de aula de inglês como } \\
\text { língua adicional. }\end{array}$ & $\begin{array}{l}\text { Laura Knijnik } 2011 \\
\text { Baumvol }\end{array}$ & $\begin{array}{l}\text { UFRGS, Letras } \\
\text { (Mestrado) }\end{array}$ \\
\hline
\end{tabular}

Fonte: Dados do período de 2004 a 2011, Banco de Teses do Portal CAPES 2012.

Esta pesquisa procurou, ainda, identificar e mapear quais os PPGs e as Instituições de Ensino Superior (IES) que produziram e publicaram sobre os OAs na área do conhecimento de Linguística e Letras (Quadro 3). Com isso, ao mapearmos os trabalhos acadêmicos produzidos pelas IES do Brasil numa leitura regional, encontramos as seguintes informações:

7 teses e dissertações foram produzidas nos estados da região sul, 5 produções foram desenvolvidas na região sudeste e 1 dissertação foi produzida na região centro-oeste. $\mathrm{Na}$ 
região sul, destacamos a Universidade Federal do Rio Grande do Sul (UFRGS) e a Universidade Católica de Pelotas (UCPel) com duas produções cada uma, as demais tiveram uma única produção no período. Sabemos que o número de produções possa ser maior, mas, neste momento da pesquisa, encontramos dificuldades para mapear todos os trabalhos. Ainda assim, a não existência de um grande número de produções concentrados em um único grupo de PPG demonstra que não há um programa que estude especificamente a temática dos OAs e, assim, julgamos que esse estudo carece de uma atenção especial.

Analisando os títulos das publicações (Quadro 2), podemos observar que muitas publicações não tratam especificamente sobre os OAs. Com isso, torna-se importante uma análise dos resumos desses trabalhos, pois através deles teremos uma visão real de como está sendo abordado o objeto de investigação, bem como quais são os objetivos dessas publicações. Dessa maneira, a seguir, apresentaremos os resultados da análise desses resumos.

\subsection{Análise dos resumos das teses e dissertações}

O propósito de análise dos resumos das 13 publicações, entre teses e dissertações, da área do conhecimento de Linguística e Letras, foi evidenciarmos quais das produções que tratam especificamente sobre os OAs e destacarmos a língua-alvo do ensino, bem como identificarmos os objetivos do emprego dessa ferramenta.

Dessa forma, constatamos que das 13 publicações somente 5 ( 1 tese e 4 dissertações) tratam especificamente sobre a temática OAs, ou seja, um total equivalente $38,46 \%$ do montante. É oportuno salientar que as demais produções (08 ou 61,54\%) constituem um "pseudo-positivo". Destinamos esta expressão para os resultados que durante a busca no Banco de Tese da CAPES, com as palavras-chave "Objetos de Aprendizagem", no campo "Assunto", apresentaram-se como positivo para a área de Linguística e Letras, mas durante a análise do resumo das teses e dissertações constatamos que somente citavam, em alguma seção do trabalho, a expressão "Objetos de Aprendizagem" sem efetivamente abordar o assunto. Com isso, constituem-se como negativo ou falso (pseudo) para o propósito de investigação. Esses resultados foram descartados, pois, neste momento, não se mostram relevantes para oferecerem dados sobre os estudos de OAs.

Nas produções que realmente tratam dos OAs (5 resultados positivos), destacamos que 3 produções são destinadas ao ensino de língua portuguesa como língua materna, 1 tem a 
finalidade de ensinar a língua inglesa como Língua Estrangeira (LE), e 1 aborda o ensino da língua espanhola como LE.

Sentimos, ainda, a necessidade de apresentar quem são os PPGs que orientam os autores dessas 5 produções, assim, 2 publicações foram realizadas no PPG de Letras da Universidade Católica de Pelotas (UCPel), 1 no PPG de Letras da Universidade Estadual do Oeste do Paraná (UNIOESTE), 1 no PPG de Linguística da Universidade Cruzeiro do Sul (UNICSUL) e 1 no PPG de Letras da Pontifícia Universidade Católica do Rio de Janeiro (PUC-RJ).

Ter uma visão geral sobre os objetivos das publicações nos proporcionaum panorama do emprego dos OAs nos PPGs dos estabelecimentos de ensinos no Brasil. No Quadro 4, estão relacionados os objetivos das 5 publicações que realmente tratam do tema OA.

Quadro 4 - Objetivos das Teses e Dissertações que tratam especificamente sobre OAs

\begin{tabular}{|c|c|}
\hline Publicação & Objetivos \\
\hline Tese & $\begin{array}{l}\text { Analisar o processo de ensino e de aprendizagem mediado por OAs. No aspecto geral, o } \\
\text { estudo propõe a elaboração de um OA pela pesquisadora, tendo, como fundamentação } \\
\text { pedagógica, alguns aspectos da teoria Histórico-cultural e sua utilização em sala de aula, em } \\
\text { uma turma de ensino fundamental da modalidade de ensino Educação de Jovens e Adultos } \\
\text { (EJA), para avaliação. }\end{array}$ \\
\hline \multirow{4}{*}{ Dissertação } & $\begin{array}{l}\text { Descrever, analisar e avaliar o conteúdo pedagógico desses objetos e detectar sua presença nos } \\
\text { cursos que propõem o ensino da língua espanhola na rede mundial de computadores. Parte-se } \\
\text { da perspectiva sócio-cultural de Vygotsky e seus seguidores, construindo-se a partir daí uma } \\
\text { proposta de instrumento de avaliação que possa aferir o valor educacional desses objetos, com } \\
\text { destaque para cinco aspectos: (1) qualidade do conteúdo; (2) usabilidade; (3) reusabilidade; (4) } \\
\text { interatividade e (5) uso de andaimes. }\end{array}$ \\
\hline & $\begin{array}{l}\text { O foco do nosso estudo sobre o Objeto de Aprendizagem Colaborativo recompõe-se a } \\
\text { partir de estudos e reflexões vivenciadas em um contexto que envolve atividades } \\
\text { desenvolvidas em forma de um Atelier com a presença de dezoito educadores dos núcleos de } \\
\text { Assis Chateaubriand, Foz do Iguaçu, Cascavel e Toledo. }\end{array}$ \\
\hline & $\begin{array}{l}\text { Com vistas a refletir sobre o que nos faz ficar tão para trás em relação ao que tem sido } \\
\text { feito na área de desenvolvimento e reutilização de objetos de aprendizagem, esta dissertação se } \\
\text { baseia na avaliação de quatro LOs produzidos por alunos de formação continuada em Mídia na } \\
\text { Educação. }\end{array}$ \\
\hline & $\begin{array}{l}\text { A pesquisa objetivou a realização de um estudo que possibilitasse a construção do } \\
\text { frame princesa dos contos de fadas por meio da exploração dos elementos descritivos, } \\
\text { focalizando a construção referencial da princesa nos contos selecionados, voltada para a } \\
\text { elaboração de um Objeto de Aprendizagem. }\end{array}$ \\
\hline
\end{tabular}

Fonte: Dados do período de 2004 a 2011, Banco de Teses do Portal CAPES 2012.

Analisando os objetivos das teses e dissertações, Quadro 4, identificamos que as publicações têm os seguintes propósitos: analisar o processo de ensino aprendizagem mediado pelos OAs; realizar um estudo reflexivo sobre a aprendizagem através dos OAs; avaliar 
quatro OAs produzidos pelos próprios alunos; descrever, analisar e avaliar o conteúdo pedagógico dos OAs; e elaborar um OA.

Identificar os pressupostos teóricos utilizados nos OAs torna-se importante para orientar e definir futuras posições que podem ser tomadas na investigação do projeto de pesquisa “A produção de OAs no ensino de E/LE”. De tal modo, direcionando o foco de análise para a perspectiva teórica utilizada nas produções, podemos destacar que os autores de 1 tese e 1 dissertação optaram pela teoria histórico-cultural do desenvolvimento humano; em outra dissertação a autora fez uso da linguística textual de linha sócio interacional cognitiva; outra autora, em sua dissertação, utilizou as principais teorias de aprendizagem de segunda língua $(\mathrm{SLLT})^{9}$ para a discussão da neutralidade teórica dos OAs; e na última dissertação a autora optou pela concepção de aprendência, mapa, rizoma e decalque para o esclarecimento e compreensão do processo de escrita e de produção dos OAs.

Durante a análise desses resumos, novamente, encontramos dificuldades em localizar os dados no Bando de Teses da CAPES. Assim, fica evidente a necessidade dos autores se preocuparem com a inclusão dos dados necessários para um bom entendimento dos resumos, os quais são descritos por Motta-Roth e Hendges (2010).

Reafirmamos, ainda, que os números apontados nessa análise, 5 entre 13 produções na área do conhecimento de Linguística e Letras, nos conduzem a uma visão que a produção de OAs é limitada e carece de um tratamento especial por parte dos pesquisadores e comunidade acadêmica. Portanto, ressaltamos que esses resultados vão ao encontro dos resultados obtidos por Leffa (2006), que aponta a necessidade de aumentar a oferta de OAs no que diz respeito ao ensino de línguas, seja estrangeira ou materna.

\section{Considerações finais}

Este estudo teve como objetivo apresentar um mapeamento a nível nacional de teses e dissertações da área do conhecimento de Linguística e Letras, que tenham como tema os OAs para o ensino e a aprendizagem de línguas. Para isso, procuramos evidenciar o que está sendo produzido e publicado referente ao tema OAs para o ensino de línguas, utilizando como meio a análise de teses e dissertações encontradas no Bando de Teses da CAPES.

\footnotetext{
${ }^{9}$ Second Language Learning Theory.
} 
Nessa análise, os resultados nos remetem a trabalhos realizados por Paiva (2005), Reis (2008) e Paiva, Silva e Gomes (2009) que destacam a necessidade e a importância de mapeamentos e estabelecimento de panoramas gerais, bem como agendas de pesquisa na área de Linguística Aplicada a fim de evidenciar o que foi produzido, o que está sendo produzido e as possibilidades de produção de artefatos pedagógicos para ensino e aprendizagem de línguas mediadas pelo computador (CALL) ${ }^{10}$.

A análise das teses e dissertações proporcionou uma visão geral sobre a produção e o emprego dos OAs, voltados para o ensino no Brasil. No sentido de visualizarmos uma possível popularização da temática, constatamos que desde o início do período investigado (2004) até o final desse período (2011), houve uma evolução significante no número de publicações, caso seja levado em consideração todas às áreas do conhecimento. No entanto, se analisarmos somente a área do conhecimento de Linguística e Letras, essa produção é muito limitada e carece de uma atenção especial por parte de estudiosos da área de Linguística Aplicada.

Essa afirmação é confirmada pelos resultados obtidos durante a análise dos OAs, pois, em um primeiro momento, tivemos um total de 229 OAs selecionados em todas as áreas do conhecimento. Já em um segundo momento, quando optamos por limitar a busca a área do conhecimento de "Linguística e Letras", esse total foi reduzido a 13 produções. Por fim, em um terceiro momento, ao analisarmos os resumos, verificamos que somente 5 produções realmente tratam exclusivamente sobre os OAs.

Ao direcionar a análise para as IES e seus respectivos PPGs, contatamos que não há uma linha de pesquisa que estude exclusivamente os OAs, pois a produção é variada em todo o Brasil. Esse resultado aponta, novamente, a necessidade de estudos e investigações que envolvam essa temática.

Na perspectiva de melhor entendermos o emprego dos OAs voltados para o ensino em sala de aula, em trabalho futuro, iremos investigar as outras áreas do conhecimento, procurando identificar o uso desses OAs para o ensino de línguas.

\footnotetext{
${ }^{10}$ Computer Assisted Language Learning.
} 


\section{Referências}

GARCIA, S. C. Objetos de aprendizagem como artefatos mediadores da construção do conhecimento: um estudo com base na Epistemologia Histórico-Cultural. 2011. 236 f. Tese (Doutorado em Letras) - Universidade Católica de Pelotas, Pelotas, 2011.

LEFFA, V. J. Nem tudo que balança cai: objetos de aprendizagem no ensino de línguas. Polifonia. Cuiabá, v. 12, n. 2, p. 15-45, 2006. Disponível em http://www.leffa.pro.br/textos/trabalhos/obj_aprendizagem.pdf. Acesso em 13 maio 2012.

LIMA, L. G. R.; HAGUENAUER, C. J. Objetos de aprendizagem: possibilidades e perspectivas na prática docente. Revista Hipertexto, v. 1, n. 2, jul./dez. 2011.

LIMA, S. C.; LIMA-NETO, V. Panorama das Pesquisas sobre letramento digital no Brasil: principais tendências. In: ARAÚJO, Júlio César; DIED, Messias (Orgs). Letramentos na web: gêneros, Interação e ensino. Fortaleza: Edições UFC, 2009. 47- 57 p.

McGREAL, R. Learning objects: A practical definition. International Journal of Instructional Technology and Distance Learning (IJITDL), v. 9, n. 1, 2004. Disponível em http://www.itdl.org/journal/sep_04/article02.htm. Acesso em 14 maio 2012.

MOTTA-ROTH, D; HENDGES, G. R. Produção textual na universidade. São Paulo: Parábola Editorial, 2010.

PAIVA, V. L. M. O. A pesquisa sobre interação e aprendizagem de línguas mediadas pelo computador. Calidoscópio. São Leopoldo, v. 3, n. 1, p. 5-12, jan/abr. 2005. Disponível em http://www.veramenezes.com/cmc.htm. Acesso em 16 junho 2012.

PAIVA, V. L. M. O.; SILVA, M. M.; GOMES, I. F. Sessenta anos de Linguística Aplicada: de onde viemos e para onde vamos. In: PEREIRA, R. C.; ROCA, P. Linguística aplicada: um caminho com diferentes acessos. São Paulo: Contexto, 2009. Disponível em http://www.veramenezes.com/linaplic.pdf. Acesso em 12 abril 2012.

REIS, S. C. As tendências teóricas em estudos de CALL no Brasil: identificando o estado da arte. In: VIII ENCONTRO DO CÍRCULO DE ESTUDOS LINGUÍSTICOS DO SUL (CELSUL). Anais...Porto Alegre - RS, 2008.

SILVA, J. T.; FAGUNDES, L. C.; BASSO, M. V. A. Metodologia para apoiar o processo de aprendizagem via autoria de objetos de aprendizagem por aluno. Revista Novas Tecnologias na Educação, CINTED - UFRGS, v. 6, n. 1, Jul. 2008. Disponível em http://seer.ufrgs.br/renote/article/viewFile/14480/8399. Acesso em 14 abril 2008.

Artigo recebido em: 15.10 .2012

Artigo aprovado em: 20.11.2012 